\title{
Tuta absoluta (Lepidoptera: Gelechiidae): Thermal requirements and effect of temperature on development, survival, reproduction and longevity
}

\author{
Flavia da Silva KRECHEMER and Luis AmiLton FOERSTER \\ Department of Zoology, Federal University of Paraná, P.O. Box 19.020, 81531-990 Curitiba, PR, Brazil; \\ e-mails: flakrechemer@gmail.com; foerster@ufpr.br
}

Key words. Lepidoptera, Gelechiidae, Tuta absoluta, tomato leafminer, degree-day, thermal requirements, fertility

\begin{abstract}
Tuta absoluta (Meyrick, 1917) is the main pest of tomato crops in South America. Recently, it was also reported in several countries in Europe and the Middle East. Because of its invasive potential and the lack of information on the biology of T. absoluta, the present study aimed to estimate its thermal requirements and evaluate the effect of temperature on its development, survival, reproduction and longevity. The experiments were carried out at constant temperatures of $10,15,20,25$ and $30^{\circ} \mathrm{C}$. T. absoluta completed its development at all these temperatures. The thermal requirements were estimated by linear regression; the insects required 416.7 degreedays to complete the cycle from egg to adult, and the lower temperature threshold was estimated to be $8.0^{\circ} \mathrm{C}$. The upper temperature threshold estimated for the egg-adult cycle was $37.3^{\circ} \mathrm{C}$. The pre-oviposition period was longer at $10^{\circ} \mathrm{C}$, but the oviposition period was similar at all the temperatures tested. Fecundity was highest at 20 and $25^{\circ} \mathrm{C}$, with averages of 134.8 and 149.1 eggs per female, respectively. The highest percentages of fertile eggs were recorded at 15,20 and $25^{\circ} \mathrm{C}$. At 10 and $30^{\circ} \mathrm{C}$, only one egg clutch was laid by $T$. absoluta. No differences were recorded in the longevity of females and males of $T$. absoluta. The tomato leaf miner can develop over a wide range of temperatures; however, its reproduction and survival were negatively affected at the extreme constant temperatures tested. The temperature variation recorded in natural environments is suitable for this pest to infest tomato crops.
\end{abstract}

\section{INTRODUCTION}

Tuta absoluta is an important pest of tomato crops in South America. For several years it was considered to be a neotropical species (Razuri \& Vargas, 1975; Moore, 1983; Michereff Filho \& Vilela, 2000). However, this species is rapidly spreading and was first recorded in 2006 in Spain and soon after in Italy, France and Greece and then in the Mediterranean Basin and currently is present in several other countries in Europe (Nel, 2009; Desneux et al., 2010; Roditakis et al., 2010; Tropea Garzia et al., 2012). This species is also reported in the Middle East (Abdul Razzak et al., 2010; Abbes et al., 2012; Baniameri \& Cheraghian, 2012). As a result, $21.5 \%$ of the area planted with tomatoes and $27.2 \%$ of its fruit produced worldwide annually is infested with T. absoluta (Desneux et al., 2011).

Several factors can influence the potential of a species to become a pest. Temperature is an extremely important abiotic factor, as it affects the development, survival and reproduction in insects (Liu et al., 1995; Hallman \& Denlinger, 1998; Ivanovic \& Nenadovic, 1999). In addition, the biological parameters of insects, as well as their thermal requirements, can also vary among different populations (Lee \& Elliott, 1998; Gomi et al., 2003). Although $T$. absoluta has become an important pest in recent years, few studies have been conducted on the effect of temperature on the biological parameters of this species (Betancourt et al., 1996; Barrientos et al., 1998; Mahdi et al., 2011; Cuthbertson et al., 2013; Mahdi \& Doumandji, 2013). In addition, there are no studies on other biological aspects, including the fertility of this species in relation to temperature. Information on all the biological parameters of a pest is essential for management planning. Given the occurrence of $T$. absoluta in areas with different climates and the lack of information on its biology, this study aimed to determine the thermal requirements of a subtropical population of T. absoluta and evaluate the effect of temperature on its development, reproduction and longevity.

\section{MATERIAL AND METHODS}

\section{Planting and maintenance of tomato plants}

Rearing and experiments with T. absoluta were conducted using leaves of tomato cultivar Santa Clara. Plants were grown in containers with approximately $3 \mathrm{~kg}$ of substrate composed of turf and lime plus minerals. To each container, $100 \mathrm{~g}$ of NPK fertilizer was added at the beginning and every 30 days. Plants were kept in a $60 \mathrm{~m}^{2}$ greenhouse $5 \mathrm{~m}$ in height.

\section{Rearing T. absoluta in the laboratory}

The stock culture of $T$. absoluta was initiated with caterpillars and pupae collected in a commercial organic cherry tomato crop, in the municipality of Colombo, Southern Brazil $\left(25^{\circ} 17^{\prime} 31^{\prime \prime} \mathrm{S}\right.$, $\left.49^{\circ} 13^{\prime} 26^{\prime \prime} \mathrm{W}\right)$.

The insects were reared at a constant temperature of $20 \pm 2^{\circ} \mathrm{C}$, $70 \pm 10 \%$ relative humidity and a 12 -h photoperiod in climate chambers. Caterpillars were kept in cages made of $2 \mathrm{~L}$ disposable bottles (PET) with the bottom removed. Tomato leaves were inserted into the bottles via the open bottom until the stem of the leaf protruded through the neck of the bottle, which was then turned upside down and placed in a glass container with water. The colony consisted of 15 bottles, each containing approximately two hundred individuals from different couples. In addition, new insects collected in the field were often added to the colony to maintain genetic variability. Adults were kept in acetate cages, $10 \mathrm{~cm}$ in diameter and $20 \mathrm{~cm}$ high. Insects were provided with cotton moistened with a $10 \%$ aqueous solution of honey placed 
in plastic lids $1 \mathrm{~cm}$ in diameter and $0.5 \mathrm{~cm}$ deep. Tomato folioles were placed in the cages for the moths to lay eggs on and the folioles with eggs were removed every three days and replaced by fresh ones.

\section{Development and survival of $T$. absoluta at different temperatures}

The experiments started after three generations were reared in the laboratory. The development and survival of immature stages of T. absoluta were evaluated at temperatures of 10, 15, 20, 25 and $30 \pm 2{ }^{\circ} \mathrm{C}, 70 \pm 10 \%$ relative humidity and a 12 -h photoperiod. For each temperature, 140 newly hatched caterpillars were individually placed in polyethylene containers $7 \mathrm{~cm}$ tall and $4 \mathrm{~cm}$ in diameter. Each larva was provided with a tomato leaflet with the petiole wrapped in moistened cotton to delay wilting. The leaflets were washed with $1 \%$ sodium hypochlorite solution prior to use. When caterpillars consumed on average $70 \%$ of the leaves or when leaves began to wilt, new leaves were provided. After caterpillars reached the pupal stage, they were removed from the leaves to determine the sex ratio using the method described by Coelho \& França (1987). The incubation period of eggs obtained from adults reared at each temperature was recorded.

\section{Reproduction and longevity of T. absoluta at different temperatures}

Adults obtained from caterpillars reared at each temperature were used to determine the fecundity and fertility of T. absoluta. There were fifteen replicates of each treatment, with each couple paired based on emergence date and kept at the same temperature as they were reared. Couples were placed in acetate cages $10 \mathrm{~cm}$ high and $10 \mathrm{~cm}$ in diameter. Every day, adults were provided with a tomato leaf for oviposition and a ball of cotton moistened with a $10 \%$ honey solution for nutrition (see "rearing of $T$. absoluta in the laboratory"). All eggs were counted and kept at the same temperature as they were laid at. Eggs were monitored daily for hatching-time and the fertility record. Mean number of fertile eggs per female was treated as a replicate. At 10 and $30^{\circ} \mathrm{C}$, only one fertile clutch of eggs was laid. Because of this, the incubation times at these temperatures were determined based on ten clutches of one hundred eggs each from females kept at $25^{\circ} \mathrm{C}$. These eggs were transferred to temperatures of 10 and $30^{\circ} \mathrm{C}$ until caterpillars hatched. Incubation time was calculated based on a total of 1000 eggs at $10^{\circ} \mathrm{C}, 848$ eggs at $15^{\circ} \mathrm{C}, 1533$ eggs at $20^{\circ} \mathrm{C}, 2309$ eggs at $25^{\circ} \mathrm{C}$ and 1000 eggs at $30^{\circ} \mathrm{C}$. Egg-laying and hatching were recorded daily in order to evaluate pre-oviposition, oviposition, lifetime fecundity, fertility and adult longevity. In addition, ten clutches of one hundred recently laid eggs from females kept at $25^{\circ} \mathrm{C}$ were transferred to $35^{\circ} \mathrm{C}$, but they did not hatch. This data was used in the nonlinear model to calculate the upper threshold temperature described below.

\section{Statistical analysis}

The effect of temperature on the immature stages, fecundity, fertility and longevity of T. absoluta was submitted to analysis of variance (ANOVA). The results were tested for homogeneity and normality using Levene and Shapiro-Wilk tests, respectively. Survival curves were produced using the Kaplan-Meier method $(P<0.05)$ (Kaplan \& Meier, 1958).

The effect of temperature on development rate was determined using a linear model to estimate the lower temperature threshold and the thermal constant (Worner, 1992) the equation for which was:

$$
1 / D=a+b T
$$

where $1 / D$ is the development rate (1/development time), $T$ is the temperature $\left({ }^{\circ} \mathrm{C}\right)$ and $a$ and $b$ are the angular and linear coefficients of the line. The lower temperature threshold $\left(T_{0}\right)$ was calculated as the ratio between angular and linear coefficients of the line $(-a / b)$, while the thermal constant $(K)$ was obtained using the quotient $1 / b$ (Campbell et al., 1974). To estimate the upper temperature threshold $\left(T_{\max }\right)$, the nonlinear model proposed by Lactin et al. (1995) was used, which is based on the equation:

$$
y=e^{(\rho T)}-e^{(p \operatorname{Tmax}-(\operatorname{Tax}-T) / \Delta)}
$$

where $y$ is the developmental rate, $T\left({ }^{\circ} \mathrm{C}\right)$ and $e, p$ and $\Delta$ are equation constants.

The lower and upper temperature threshold, as well as the thermal constant, obtained using the linear and nonlinear models, were estimated for each immature stage and for the whole life cycle, from egg to adult, of T. absoluta.

The effect of temperature on pre-oviposition period, lifetime fecundity and fertility, as well as oviposition period and adult longevity were evaluated by polynomial regression, using the following equations:

$$
\begin{aligned}
& y=a+b T+c T^{2}+d T^{3} \\
& y=a+(b / T)+\left(c / T^{2}\right)
\end{aligned}
$$

where $y$ is the mean of number of eggs laid, percentage fertility or mean adult longevity, $T\left({ }^{\circ} \mathrm{C}\right)$ and $a, b, c$ and $d$ are the parameters to be estimated.

The statistical analyses were carried out using software Statistica v. 7 (Statsoft, 2004) and Table Curve 2D (Systat Inc, 2002).

\section{RESULTS}

\section{Development of $T$. absoluta at different temperatures}

This species completed its development at all the temperatures used. Temperature significantly influenced the development cycle of the insect from egg to adult $\left(F_{(4,255)}=\right.$ 3266.6; $P<0.001)$, which was 18.3 and 115.4 days at 30 and $10^{\circ} \mathrm{C}$, respectively. The incubation period was 2.5 days at $30^{\circ} \mathrm{C}$ and 24.4 days at $10^{\circ} \mathrm{C}$, with significant differences between the results for all the temperatures used $\left(F_{(4,432)}=\right.$ 1089.9; $P<0.001)$ (Table 1). Larval development was also affected by temperature $\left(F_{(4,377)}=2119.0 ; P<0.001\right)$, taking 56.4 days at $10^{\circ} \mathrm{C}$ and 10.4 days at $30^{\circ} \mathrm{C}$. The duration of the pupal phase $\left(F_{(4,255)}=651.4 ; P<0.001\right)$ was also inversely proportional to temperature (Table 1$)$.

TABLE 1. Development time (days) (Mean $\pm \mathrm{SE}$ ) of the different life stages of Tuta absoluta recorded at five constant temperatures.

\begin{tabular}{lcccc}
\hline \multirow{2}{*}{ Temperature } & \multicolumn{3}{c}{ Immature stages (days) } & \multirow{2}{*}{ Egg-adult cycle } \\
\cline { 2 - 4 } & \multicolumn{1}{c}{ Egg } & Larvae & Pupae & $115.4 \pm 1.3$ \\
$10^{\circ} \mathrm{C}$ & $24.4 \pm 0.3$ & $56.4 \pm 1.1$ & $36.8 \pm 0.7$ & $63.9 \pm 0.8$ \\
$15^{\circ} \mathrm{C}$ & $11.9 \pm 0.3$ & $34.1 \pm 0.6$ & $18.4 \pm 0.4$ & $34.8 \pm 0.2$ \\
$20^{\circ} \mathrm{C}$ & $6.9 \pm 0.1$ & $17.8 \pm 0.2$ & $10.2 \pm 0.1$ & $23.5 \pm 0.3$ \\
$25^{\circ} \mathrm{C}$ & $4.5 \pm 0.1$ & $11.0 \pm 0.1$ & $8.4 \pm 0.3$ & $18.3 \pm 0.2$ \\
$30^{\circ} \mathrm{C}$ & $2.5 \pm 0.1$ & $10.4 \pm 0.2$ & $5.4 \pm 0.2$ & \\
\hline
\end{tabular}



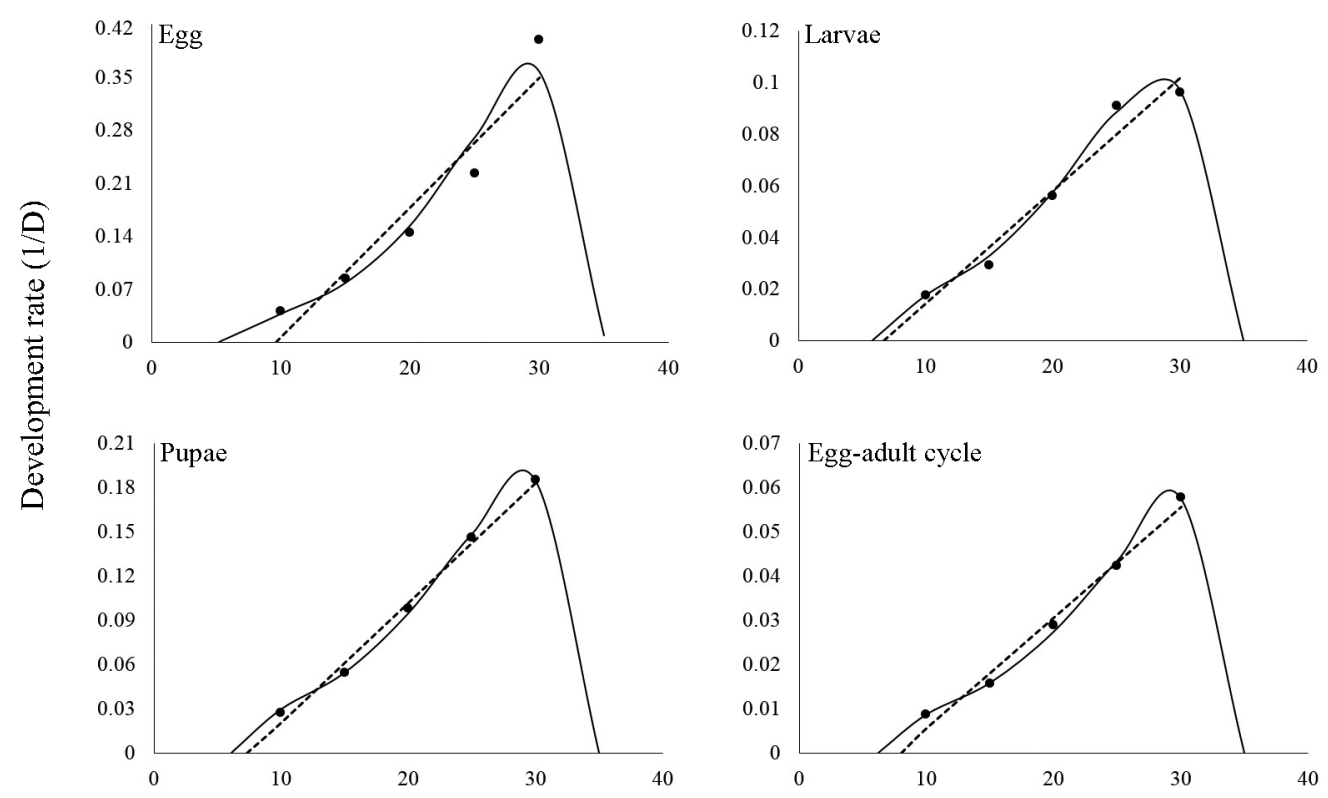

Temperature $\left({ }^{\circ} \mathrm{C}\right)$

Fig. 1. Curve fitting $(\bullet-$ observed; -- - linear regression; - - nonlinear model) of the mathematical models used to describe the relationship between development rate $(1 / D)$ and temperature for Tuta absoluta.

The lower developmental threshold estimated using the linear model for the egg-adult cycle was $8.0^{\circ} \mathrm{C}$ with a thermal constant of 416.7 degree-days (Table 2). The upper developmental threshold for the egg-adult cycle estimated using the nonlinear model was $37.3^{\circ} \mathrm{C}$. The $T_{0}$ and $T_{\max }$ estimated for each development stage of $T$. absoluta, and the corresponding thermal constants are presented in Table 2. The fit of the linear and nonlinear models to the development rates recorded at the different temperatures is shown in Fig. 1.

\section{Survival of T. absoluta at different temperatures}

The extreme temperatures had a negative effect on the survival of $T$. absoluta. The percentage survival of the eggs at $10(4.0 \%)$ and $30^{\circ} \mathrm{C}(1.3 \%)$ were significantly lower than at $15(80.6 \%), 20(67.2 \%)$ and $25^{\circ} \mathrm{C}(81.0 \%)\left(\chi_{(4)}^{2}=\right.$ 4.22). No differences in survival were recorded for larvae at the different temperatures $\left(\chi^{2}{ }_{(4)}=0.07\right)$, but it ranged from $42.1 \%$ at $10^{\circ} \mathrm{C}$ to $80.8 \%$ at $25^{\circ} \mathrm{C}$. Temperature did not significantly affect the survival of pupae $\left(\chi_{(4)}^{2}=0.00\right)$, which ranged from $52.5 \%$ at $10^{\circ} \mathrm{C}$ to $83.5 \%$ at $25^{\circ} \mathrm{C}$. The shapes of the survival curves significantly depended on temperature $\left(\chi_{(4)}^{2}=58.56 ; P<0.05\right)$, with the lifespan inversely proportional to temperature (Fig. 2).

\section{Reproduction and longevity of $T$. absoluta at different temperatures}

Temperature significantly affected the pre-oviposition period $\left(F_{(4,61)}=13.71 ; P<0.001\right)$, fecundity $\left(F_{(4,61)}=17.39\right.$; $P<0.001)$ and fertility $\left(F_{(4,61)}=66.51 ; P<0.001\right)$ of $T . a b$ soluta, but not oviposition $\left(F_{(4,61)}=2.10 ; P=0.09\right)$.

The pre-oviposition period at $10^{\circ} \mathrm{C}$ was 9.5 days and significantly longer than at the other temperatures. The oviposition period ranged from 9.5 days at $30^{\circ} \mathrm{C}$ to 15.4 days at $20^{\circ} \mathrm{C}$ (Table 3). Fecundity was highest at 20 and $25^{\circ} \mathrm{C}$, with averages of 134.8 and 149.1 eggs per female, respectively. Females maintained at these temperatures, along with those at $15^{\circ} \mathrm{C}$ had the highest percentages of fertile eggs (Table 3 ).

Temperature inversely affected the longevity of females and males of $T$. absoluta $\left(F_{(4,52)}=11.09 ; P<0.001 ; F_{(4,52)}=\right.$ $3.53 ; P=0.01$, respectively), but at $10^{\circ} \mathrm{C}$, although not sig-

TABLE 2. The lower developmental threshold temperature $\left(T_{0}\right)$, thermal constant in degree-days $(K)$ and upper developmental threshold $\left(T_{\max }\right)$ estimated for the immature stages of Tuta absoluta using linear and nonlinear models.

\begin{tabular}{lccccc}
\hline \multirow{2}{*}{ Model type } & \multirow{2}{*}{ Parameters } & \multicolumn{3}{c}{ Life stages of Tuta absoluta } & \multirow{2}{*}{ Egg-adult cycle } \\
\cline { 3 - 5 } & & Egg & Larvae & Pupae & -0.0175 \\
& $a$ & -0.1641 & -0.0293 & -0.0555 & 0.0024 \\
Regression linear & $b$ & 0.0171 & 0.0044 & 0.0076 & $8.0 \pm 0.08$ \\
& $T_{0}\left({ }^{\circ} \mathrm{C}\right)$ & $9.6 \pm 0.36$ & $6.7 \pm 0.11$ & $7.3 \pm 0.05$ & $416.7 \pm 34.72$ \\
& $K$ & $58.5 \pm 9.92$ & $227.3 \pm 25.83$ & $131.6 \pm 6.93$ & 0.99 \\
\hline \multirow{3}{*}{ Lactin model } & $r^{2}$ & 0.91 & 0.96 & $36.0 \pm 0.81$ & $37.3 \pm 1.47$ \\
& $T_{\max }\left({ }^{\circ} \mathrm{C}\right)$ & $35.1 \pm 0.21$ & $34.3 \pm 0.7$ & 0.00 & 0.00 \\
& $p$ & 0.01 & 0.00 & 0.99 & 0.99 \\
\hline
\end{tabular}




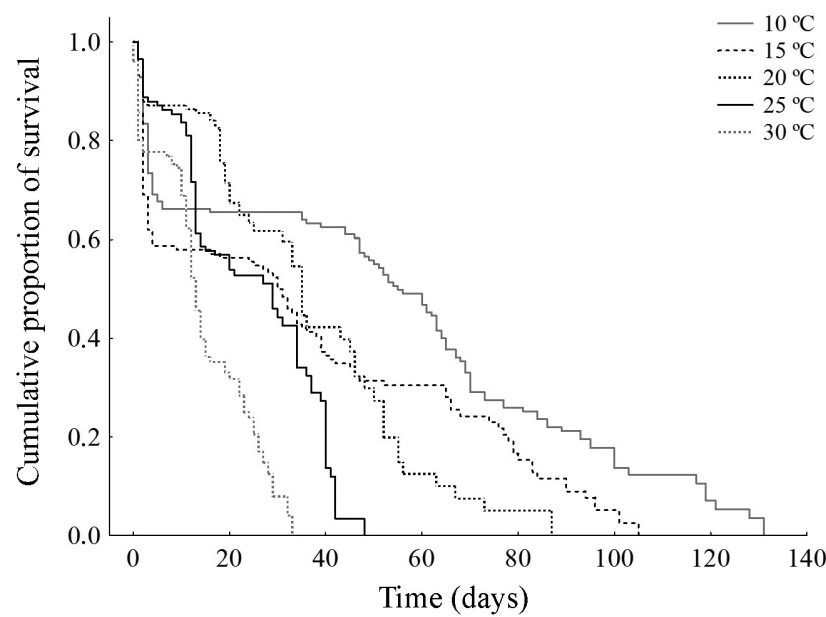

Fig. 2. Survival curves of males and females of Tuta absoluta recorded at five constant temperatures $\left(10,15,20,25\right.$ and $\left.30^{\circ} \mathrm{C}\right)$.

nificantly different, lifespan tended to be shorter than that recorded at $15^{\circ} \mathrm{C}$. The longevity of females kept at $30^{\circ} \mathrm{C}$ was significantly less than that of those kept at 10,15 and $20^{\circ} \mathrm{C}$. There were no significant differences in the lifespan of males and females (Table 4). The polynomial functions provided a good fit to the relationship between pre-oviposition and oviposition periods, fecundity, lifetime fertility and adult longevity, and temperature (Table 5).

\section{DISCUSSION}

Temperature affected the development, reproduction and longevity of T. absoluta. In nature, insects are often exposed to stressful conditions, such as extreme temperatures, and consequently are tolerant and adapted to withstand such conditions (Levins, 1969; Hoffmann \& Parsons, 1991). There are some studies of the relationship between the biological characteristics of T. absoluta and temperature (Bentancourt et al., 1996; Barrientos et al., 1998; Mahdi et al., 2011; Cuthbertson et al., 2013; Mahdi \& Doumandji, 2013). However, there are no studies on the mean egg viability and upper temperature threshold of this species. Thus, the results of our study may be helpful in the future for developing more effective ways of controlling this species.

T. absoluta completed its development at all the temperatures used, whereas in the United Kingdom Cuthbertson et al. (2013) failed to obtain adults at $10^{\circ} \mathrm{C}$. Similar studies conducted in Chile (Barrientos et al., 1998) and in Uruguay (Bentancourt et al., 1996) report longer development times than those recorded in our study. Different populations of the same species may have different development
TABLE 4. Mean $( \pm$ SE) longevity of females and males of Tuta absoluta recorded at five constant temperatures $(10,15,20,25$ and $30^{\circ} \mathrm{C}$ ).

\begin{tabular}{lcc}
\hline \multirow{2}{*}{ Temperature } & \multicolumn{2}{c}{ Longevity (days) } \\
\cline { 2 - 3 } & Female & Male \\
\hline $10^{\circ} \mathrm{C}$ & $32.3 \pm 2.8$ & $17.5 \pm 6.9$ \\
$15^{\circ} \mathrm{C}$ & $34.9 \pm 3.9$ & $30.0 \pm 4.5$ \\
$20^{\circ} \mathrm{C}$ & $26.6 \pm 2.1$ & $23.7 \pm 3.5$ \\
$25^{\circ} \mathrm{C}$ & $20.1 \pm 1.8$ & $16.9 \pm 2.3$ \\
$30^{\circ} \mathrm{C}$ & $10.8 \pm 1.4$ & $9.0 \pm 1.3$ \\
\hline
\end{tabular}

parameters (Lee \& Elliott, 1998; Gomi et al., 2003). The above mentioned studies used populations of T. absoluta from South America and the United Kingdom, and this may be one of the factors responsible for the reported differences in the effect of temperature on the development of T. absoluta. In addition, the authors of these studies did not mention for how many generations the insects were kept in the laboratory before the experiments and although the effect of this trait on T. absoluta has not been determined, it may have affected the results. Other factors might also have affected the development time, such as the quality of the food provided and experimental conditions (i.e. photoperiod and humidity). Different tomato cultivars can influence the development time and adult size of T. absoluta (Gharekhani \& Salek-Ebrahimi, 2014). In the above studies, Bentancourt et al. (1996) used a different cultivar to that used in our study, and the other authors did not mention which cultivar they used. It is therefore probable that the nature of the food source used affected the results.

The lower developmental threshold temperature estimated for the egg-adult cycle of T. absoluta was $8.0^{\circ} \mathrm{C}$, which is similar to that obtained by other authors, namely $8.1^{\circ} \mathrm{C}$ (Barrientos et al., 1998) and $8.0^{\circ} \mathrm{C}$ (Bentancourt et al., 1996). However, it was lower than that recorded by Mahdi et al. (2011) and Mahdi \& Doumandji $(2013)\left(9.8^{\circ} \mathrm{C}\right)$ for this species in Algeria, despite using very similar experimental conditions. This difference is probably an adaptation of $T$. absoluta to the high temperatures prevailing in Algeria. The lower base temperature estimated for the larval stage $\left(6.7^{\circ} \mathrm{C}\right)$ in our study is also similar to the results of Bentancourt et al. (1996) $\left(6.0^{\circ} \mathrm{C}\right)$ and Mahdi \& Doumandji (2013) $\left(6.2^{\circ} \mathrm{C}\right)$. T. absoluta is a leaf miner during its larval stage and some studies have shown that the microclimate within the tunnels tends to be favourable for this insect. The temperature inside the tunnels is usually warmer than that on the surface of the leaf (Connor \& Taverner, 1997; Pincebourde \& Casas, 2006; Pincebourde \& Woods, 2012). This may enable T. absoluta to tolerate lower temperatures

TABLE 3. Mean duration $( \pm \mathrm{SE})$ of the pre-oviposition and oviposition periods, fecundity (eggs per female) and egg viability (\%) of Tuta absoluta recorded at five constant temperatures $\left(10,15,20,25\right.$ and $\left.30^{\circ} \mathrm{C}\right)$.

\begin{tabular}{lcccc}
\hline Temperature & Pre-oviposition period (days) & Oviposition period (days) & Lifetime fecundity (eggs) & Egg viability (\% hatch) \\
\hline $10^{\circ} \mathrm{C}$ & $9.5 \pm 2.4$ & $14.5 \pm 6.9$ & $35.5 \pm 20.4$ & $4 \pm 4$ \\
$15^{\circ} \mathrm{C}$ & $3.3 \pm 0.7$ & $14.6 \pm 1.7$ & $76.4 \pm 9.3$ & $80.6 \pm 6.2$ \\
$20^{\circ} \mathrm{C}$ & $2.0 \pm 0.2$ & $15.4 \pm 1.4$ & $134.8 \pm 13.3$ & $67.2 \pm 2.4$ \\
$25^{\circ} \mathrm{C}$ & $2.3 \pm 0.2$ & $11.6 \pm 0.9$ & $149.1 \pm 11.8$ & $81.0 \pm 3.6$ \\
$30^{\circ} \mathrm{C}$ & $1.9 \pm 0.2$ & $9.5 \pm 1.5$ & $26.2 \pm 6.2$ & $1.3 \pm 1.3$ \\
\hline
\end{tabular}


TABLE 5. Estimated parameters of the models used to describe the relationship between the adult life history traits of Tuta absoluta and temperature.

\begin{tabular}{|c|c|c|c|c|}
\hline Models type & Parameters* & Estimate & SEM & $r^{2}$ \\
\hline \multirow{3}{*}{ Pre-oviposition period model } & $a$ & 5.78 & 1.20 & \multirow{3}{*}{0.99} \\
\hline & $b$ & -183.82 & 40.23 & \\
\hline & $c$ & 2209.09 & 295.56 & \\
\hline \multirow{4}{*}{ Oviposition period model } & $a$ & -126.51 & 264.69 & \multirow{4}{*}{0.92} \\
\hline & $b$ & 57.107 & 44.87 & \\
\hline & $c$ & -2.75 & 2.34 & \\
\hline & $d$ & 0.036 & 0.04 & \\
\hline \multirow{4}{*}{ Fecundity model } & $a$ & 82407.67 & 725.38 & \multirow{4}{*}{0.99} \\
\hline & $b$ & -17451.51 & 134.16 & \\
\hline & $c$ & 1155.08 & 7.53 & \\
\hline & $d$ & -22.14 & 0.13 & \\
\hline \multirow{4}{*}{ Fertility model } & $a$ & -18551.60 & 19287.54 & \multirow{4}{*}{0.93} \\
\hline & $b$ & 2454.16 & 3513.60 & \\
\hline & $c$ & -58.99 & 190.59 & \\
\hline & $d$ & -0.07 & 3.17 & \\
\hline \multirow{3}{*}{ Longevity male model } & $a$ & -44.54 & 2.42 & \multirow{3}{*}{0.99} \\
\hline & $b$ & 2118.19 & 81.10 & \\
\hline & $c$ & -14980.13 & 595.86 & \\
\hline \multirow{3}{*}{ Longevity female model } & $a$ & -38.21 & 5.35 & \multirow{3}{*}{0.99} \\
\hline & $b$ & 1897.61 & 179.18 & \\
\hline & $c$ & 11934.54 & 1316.47 & \\
\hline
\end{tabular}

$* a, b, c$ and $d$ are fitted parameters; $r^{2}$ - coefficient of determination.

during its larval stage. The upper developmental threshold temperature estimated for the egg-adult cycle of T. absoluta was $37.3^{\circ} \mathrm{C}$. This result, combined with the estimated lower temperature threshold indicates that this species can survive over a wide temperature range, which is likely to have enabled it to spread worldwide.

The heat accumulation needed for T. absoluta to complete its development recorded in the present study was 416.7 degree-days. The thermal constant reported by other authors is higher than that obtained in our study, with an additional 30 to 40 degree-days required for this insect to complete its cycle from egg to adult (Bentancourt et al., 1996; Barrientos et al., 1998). The authors of these studies used different methods to calculate the lower developmental threshold and thermal requirements than the one used in our study. However, different methods for estimating the base temperature and thermal constant typically result in small differences in the final values. Thus, the differences in the results obtained in our study and those mentioned above should not be attributed to the methods used.

The survival of T. absoluta was negatively affected by the extreme temperatures used. The shapes of the survival curves are typical for holometabolous insects, with survival differing greatly for the successive stages in the life cycle (Odum \& Barrett, 2007). The percentage survival of recently hatched larvae kept at 10,15 and $30^{\circ} \mathrm{C}$ was particularly low. In these cases, newly-emerged caterpillars were most likely not able to penetrate the leaf. Cuthbertson et al. (2013) report similar results, with only $3 \%$ pupating and no adults emerging at $10^{\circ} \mathrm{C}$. These authors also found that the emergence of adults also decreases at high temperatures. The results of the present study can be explained by the low tolerance of this species of extreme temperatures, as indicated by the low fertility of T. absoluta at these temperatures, and partly by the stress caused by the experimental conditions. Furthermore, under natural conditions, this insect can complete its development in a single leaf, as it takes longer to deteriorate under these conditions than in the experimental conditions. Therefore, the low percentage survival recorded during the development of $T$. absoluta reared under laboratory conditions was possibly higher than those experienced under natural conditions.

In our study, no differences were recorded between the longevity of males and females. This is also reported by Imenes et al. (1990), who compared the longevity of couples fed and not fed a honey solution (10\%) and recorded an average longevity of 36.5 days for males and 31.7 days females at an average temperature of $18.5^{\circ} \mathrm{C}$, with no significant differences between these values. The authors report that the fed insects survived the longest.

Although T. absoluta completed its development and females laid eggs at all temperatures, eggs kept at 10 and $30^{\circ} \mathrm{C}$ were infertile. In several regions of Brazil, this species occurs at warm periods of the year. In protected crops, temperatures may reach $40^{\circ} \mathrm{C}$ or more at some time during the day. The most likely explanation is that if an insect experiences a constant extreme temperature during its development this affects its reproduction. Bentancourt et al. (1996) report that females of T. absoluta kept at 12 or $30^{\circ} \mathrm{C}$ do not lay eggs. In this same study, the authors maintained larvae of $T$. absoluta at average temperatures of 20 and $25^{\circ} \mathrm{C}$ during their development and after adult emergence transferred them to either 12 or $30^{\circ} \mathrm{C}$, and their fecundity was similar to that recorded in the other treatments.

Our results indicate that T. absoluta is able to develop over a wide range of temperatures. However, its repro- 
duction is negatively affected at extreme constant temperatures. Its survival is affected by extreme temperatures, mainly in the early stages of development. Temperature variations in natural environments provide suitable conditions for this species to infest tomato crops.

ACKNOWLEDGEMENTS. The authors thank the Brazilian National Research Council (CNPq) for scholarship and financial support and C.A. Marchioro for statistical support.

\section{REFERENCES}

Abbes K., Harbi A. \& Chermiti B. 2012: The tomato leafminer Tuta absoluta (Meyrick) in Tunisia: current status and management strategies. - Bull. EPPO 42: 226-233.

Abdul RazzaK A.S., Yassiri A.L. \& Fadhil H.Q. 2010: First report of tomato borer (tomato moth) Tuta absoluta (Meyrick) (Lepidoptera: Gelechidae) on tomato crop in Iraq. - Arab Near East Plant Prot. Newsl. 51: 31.

Baniameri V. \& Cheraghian A. 2012: The first report and control strategies of Tuta absoluta in Iran. - Bull. EPPO 42: 322-324.

Barrientos R.Z., Apablaza H.J., Norero S.A. \& Estay P.P. 1998: Temperatura base y constante térmica de desarrollo de la polilla del tomate, Tuta absoluta (Lepidoptera: Gelechiidae). Cienc. Investig. Agrar. 25: 133-137.

Bentancourt C.M., Scatoni I.B. \& Rodríguez J.J. 1996: Influencia de la temperatura sobre la reproducción y el desarrollo de Scrobipalpuloides absoluta (Meyrick) (Lepidoptera, Gelechiidae). - Rev. Bras. Biol. 56: 661-670.

Campbell A., Frazer B.D., Gutierrez A.P. \& Macknauer A.P. 1974: Temperature requirements of some aphids and their parasites. - J. Appl. Ecol. 11: 431-438.

Coelho M.C.F. \& França F.H. 1987: Biologia, quetotaxia da larva e descrição da pupa e adulto da traça-do-tomateiro. - Pesq. Agropec. Bras. 22: 129-135.

ConNor E.F. \& TAVERner M.P. 1997: The evolution and adaptive significance of the leaf-mining habitat. - Oikos 76: 6-25.

Cuthbertson A.G.C., Mathers J.J., Blackburn L.F.M., KorycinSKA W.L., Luo W., Jacobson R.J. \& Northing P. 2013: Population development of Tuta absoluta (Meyrick) (Lepidoptera: Gelechiidae) under simulated UK glasshouse conditions. - Insects 4: 185-197.

Desneux N., Wajnberg E., Kris A.G., Wyckhuys A.G.K., Burgio G., Arpaia S., Narvaez-Vasquez C.A., Gonzalez-Cabrera J., Catalan Ruescas D., Tabone E., Frandon J., Pizzol J., Poncet C., Cabello T. \& Urbaneja C.A. 2010: Biological invasion of European tomato crops by Tuta absoluta: ecology, geographic expansion and prospects for biological control. - J. Pest Sci. 83: $197-215$.

Desneux N., Luna M.G., Guillemaud T. \& Urbaneja A. 2011: The invasive South American tomato pinworm, Tuta absoluta, continues to spread in Afro-Eurasia and beyond: the new threat to tomato world production. - J. Pest Sci. 84: 403-408.

Gharekhani G.H. \& Salek-Ebrahimi H. 2014: Life table parameters of Tuta absoluta (Lepidoptera: Gelechiidae) on different varieties of tomato. - J. Econ. Entomol. 107: 1765-1770.

Gomi T., InUdo M. \& Yamada D. 2003: Local divergence in developmental traits within a trivoltine area of Hyphantria cunea Drury (Lepidoptera: Arctiidae). - Entomol. Sci. 6: 71-75.

Hallman G.J. \& Denlinger D.L. 1998: Introduction: temperature sensitivity and integrated pest management. In Hallman G.J. \& Denlinger D.L. (eds): Temperature Sensitivity in Insects and Application in Integrated Pest Management. Westview Press, Boulder, pp. 1-6.

Hoffmann A.A. \& Parsons P.A. 1991: Evolutionary Genetics and Environmental Stress. Oxford University Press, Oxford, 294 pp.
Imenes S.D.L., UchôA Fernandes M.A., CAmpos T.B. \& TakeMATSU A.P. 1990: Aspectos biológicos e comportamentais da traça-do-tomateiro Scrobipalpula absoluta (Meyrick, 1917), (Lepidoptera - Gelechiidae). - Arq. Inst. Biol. 57: 63-68.

Ivanovic J. \& Nenadovic V. 1999: The effect of diet and temperature on the life cycle of phytophagous insects. - Pesticides 14: 309-327.

KaPLAN E.L. \& MeIER P. 1958: Nonparametric estimation from incomplete observations. - J. Am. Statist. Assoc. 53: 457-481.

Lactin D.J., Holliday N.J., Johnson D.L. \& Craigen R. 1995: Improved rate model of temperature-dependent development by arthropods. - Environ. Entomol. 24: 68-75.

LeE J.H. \& ElLIotT N.C. 1998: Comparison of developmental responses to temperature in Aphelinus asychis (Walker) from two different geographic regions. - Southwest. Entomol. 23: 77-82.

LEVINS R. 1969: Thermal acclimation and heat resistance in Drosophila species. — Am. Nat. 103: 483-499.

LiU S.S., Zhang G.M. \& ZHU J. 1995: Influence of temperature variations on rate of development in insects: analysis of case studies from entomological literature. - Ann. Entomol. Soc. Am. 88: 109-117.

Mahdi K. \& Doumandi S. 2013: Research on temperature: limiting factor of development of tomato leaf miner Tuta absoluta (Meyrik) (Lepidoptera: Gelechiidae). - Int. J. Agric. Sci. Res. 4: $81-88$.

Mahdi K., Doumandu-Mitiche B. \& Doumandi S. 2011: Effect of temperature on the development cycle of the tomato leafminer Tuta absoluta in Algiers. In: Proc. AFPP - 9. Conférence Internationale sur les Ravageurs en Agriculture, Montpellier, 26.-27. Octobre 2011. Montpellier, pp. 308-316.

Michereff Filho M. \& Vilela E.F. 2000: Traça-do-tomateiro, Tuta absoluta (Lepidoptera: Gelechiidae). In Vilela E.F., Zucchi R.A. \& Cantor F. (eds): Pragas introduzidas. Holos, São Paulo, 173 pp.

Moore J.E. 1983: Control of tomate leafminer (Scrobipalpula absoluta) in Bolívia. - Trop. Pest. Manag. 29: 231-238.

NeL J. 2009: Confirmation of the presence of the tomato pest Tuta absoluta (Lepidoptera, Gelechiidae) (Meyrick, 1917), in southern France. - Bull. Soc. Entomol. Fr. 114: 427-428.

Odum E.P. \& Barrett G.W. 2007: Fundamentos de Ecologia. Thomson, São Paulo, 612 pp.

Pincebourde S. \& CASAs J. 2006: Multitrophic biophysical budgets: thermal ecology of an intimate herbivore insect-plant interaction. - Ecol. Monogr. 76: 175-194.

Pincebourde S. \& Woods H.A. 2012: Climate uncertainty on leaf surfaces: the biophysics of leaf microclimates and their consequences for leaf-dwelling organisms. - Funct. Ecol. 26: 844-853.

RAzURI V. \& VARgas E. 1975: Biologia e comportamiento de Scrobipalpula absoluta Meyrick (Lep., Gelechiidae) en tomatera. - Rev. Peru. Entomol. 18: 84-89.

Roditakis E., Papachristos D. \& Roditakis N.E. 2010: Current status of the tomato leafminer Tuta absoluta in Greece. - Bull. EPPO 40: 163-166.

Statsoft Inc. 2004: Software Statistica 7.0. EUA.

Systat Inc. 2002: Table Curve 2D. Systat Software Inc., Chicago, EUA.

Tropea Garzia G., Siscaro G., Biondi A. \& Zappalà L. 2012: Tuta absoluta, a South American pest of tomato now in the EPPO region: biology, distribution and damage. - Bull. EPPO 42: $205-210$.

WORNER S.P. 1992: Performance of phenological models under variable temperature regime: consequences of the Kaufmann or rate summation effect. - Environ. Entomol. 1: 689-699.

Received December 23, 2014; revised and accepted September 14, 2015 Prepublished online October 8, 2015 